${ }^{\circ}$ Entomologica Fennica. 19 September 2003

\title{
Taxonomic studies on the subtribe Aphrastobraconina Ashmead (Hymenoptera: Braconidae: Braconinae) in China
}

\author{
Yi-ping Wang, Xue-xin Chen* \& Jun-hua He
}

\author{
Wang, Y., Chen, X. \& He, J. 2003: Taxonomic studies on the subtribe \\ Aphrastobraconina Ashmead (Hymenoptera: Braconidae: Braconinae) in China. \\ — Entomol. Fennica 14: 118-124.
}

The species of the subtribe Aphrastobraconina Ashmead from China were studied and five species belonging to three genera (Undabracon Quicke, 1986, Curriea Ashmead, 1900 and Aphrastobracon Ashmead, 1896) recognized. Three new species (Undabracon cariniventris sp. n., Aphrastobracon huanjiangensis sp. $\mathrm{n}$. and A. politus sp. n.) are fully described and illustrated. The genus Undabracon (Quicke, 1986), the species Aphrastobraconflavipennis Ashmead and Curriea tibialis (Ashmead) are reported for the first time from China. A key to the species of the genus Undabracon is provided.

Yi-ping Wang, Xue-xin Chen \& Jun-hua He, Institute of Applied Entomology, College of Agriculture and Biotechnology, Zhejiang University, Hangzhou 310029,China (*E-mail: xxchen@zju.edn.cn)

Yi-ping Wang, Department of Biology, College of Life Science, Zhejiang Forestry College, Lin'an 311300, China

Received 2 January 2003, accepted 30 April 2003

\section{Introduction}

Based on the nature of the far antefurcal vein cua and ovoid subdiscal cell of fore wing, Aphrastobracon Ashmead was placed in its own tribe Aphrastobraconini for the first time by Ashmead (1900). According to morphological and molecular phylogenetic studies, Quicke $(1988,2000)$ considered it as a subtribe Aphrastobraconina. Currently it consists of eight genera, namely Aphrastobracon Ashmead, 1896, Cedilla Quicke, 1990, Curriea Ashmead, 1900 (subgenera Curriea Ashmead and Endovipio Turner, 1922), Eucurriea Quicke, 1990, Hewittella Cameron, 1906, Ligulibracon Quicke, 1986, Megalommum Szépligeti, 1900 and Undabracon Quicke, 1986. Most taxonomists have recognized that the genus Aphrastobracon is closely related to the genera
Curriea and Megalommum (e.g. Ashmead 1900), whereas some authors have considered the latter two genera to be synonyms of Aphrastobracon (Fahringer 1928, Watanabe 1950, Baltazar 1963, Papp 1972, Shenefelt 1978, Tobias 1968). However, at present they all have been regarded as separate genera and can be identified by the keys provided by Quicke (1987), Quicke and Ingram (1993) and Quicke et al. (2000).

In the present paper, we sort the genera of the subtribe Aphrastobraconina from China. Five species belonging to the genera Aphrastobracon Ashmead, Curriea Ashmead and Undabracon Quicke are recognized, three of which (Undabracon cariniventris sp. n., Aphrastobracon huanjiangensis sp. n. and Aphrastobracon politus sp. n.) are new to science, and fully described and illustrated (see Results chapter). Aphrastobracon 
flavipennis Ashmead, Curriea tibialis (Ashmead) and the genus Undabracon Quicke are reported for the first time in China. A key to the species of Undabracon is provided. The type and other voucher specimens are kept in the Parasitic Hymenoptera Collection, Zhejiang University, Hangzhou, China.

The morphological terminology used in this paper follows that of van Achterberg (1979) and Quicke (1987).

\section{Taxonomy of Aphrastobraconina in China}

\subsection{Genus Undabracon Quicke}

Undabracon Quicke, 1986: Ent. Mon. Mag. 122: 22-23; Quicke (1987): J. Nat. Hist. 21: 135; Quicke \& Ingram (1993): Mem. Queensland Mus. 33: 332; Falco \& Quicke (1997): Eur. J. Ent. 94: 547; Quicke et al. (2000): African Ent. 8: 110. Type species (monobasic and original designation): Undabracon nigrithorax Quicke.

The Undabracon Quicke is a small genus with two known species distributed in Australia and the Philippines. Below we provide a key to the Undabracon Quicke species and describe a new species, Undabracon cariniventris sp. n.

\subsubsection{Key to the species of Undabracon Quicke}

1. Vein cu-a of fore wing far antefurcal (Fig. 1d); ocellar triangle area brown; ovipositor with two or three strongly arch-like parts (Fig. 11)

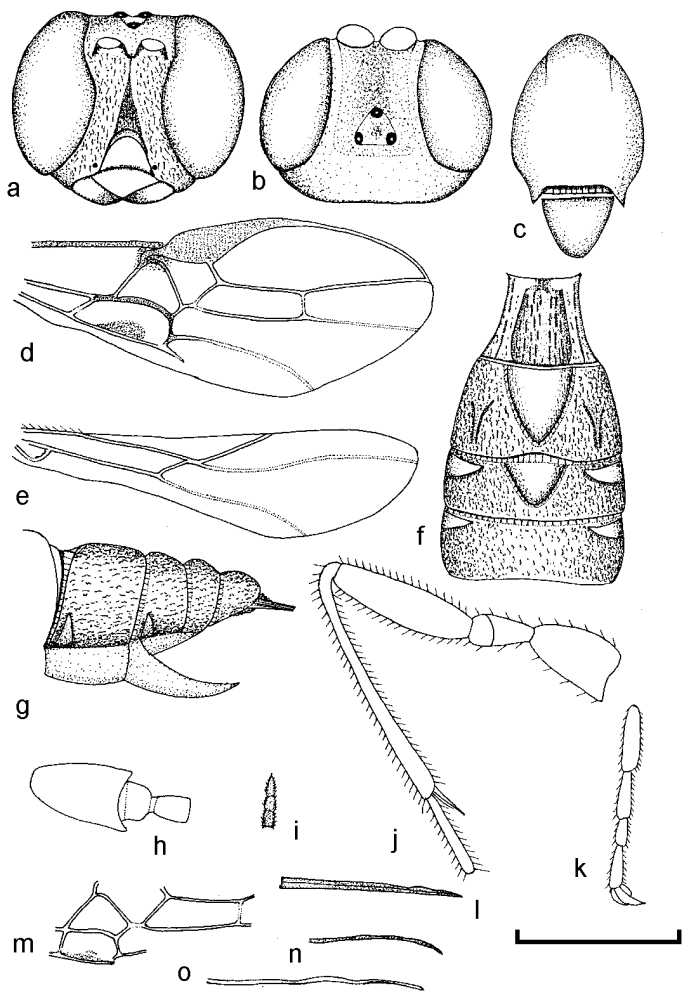

Fig. 1. - a-I. Undabracon cariniventris sp. n., holotype female. - m-n. Undabracon nigrithorax Quicke. - o. Undabracon sinuatus Baltazar. $\mathrm{a}=$ head, frontal aspect; $\mathrm{b}=$ head, dorsal aspect; $\mathrm{c}=$ mesothorax, dorsal aspect; $d=$ fore wing; $e=$ hind wing; $f=$ firstfourth metasomal tergites, dorsal aspect; $g=$ thirdsixth metasomal tergites, lateral aspect; $h=$ scapus, pedicellus and first flagellomere; $\mathrm{i}=$ terminal and subterminal flagellomeres; $\mathrm{j}=$ hind leg; $\mathrm{k}=$ tarsus of hind leg; $m=$ partial venation of fore wing; $I, n$, $\mathrm{o}=$ ovipositor. Figures $\mathrm{m}$ and $\mathrm{n}$ redrawn after Quicke (1986) and figure o after Baltazar (1963). Scale bar: $2 \times(\mathrm{a}-\mathrm{j}, \mathrm{l}) ; 2.5 \times(\mathrm{k})$. weakly arch-like parts (Australia) (Fig. 1n) Undabracon nigrithorax Quicke

2. Second discal cell of fore wing with a dark brown spot; ovipositor with three arch-like parts (the Philippines) (Fig. 1o) ................ Undabracon sinuatus (Baltazar)

- Second discal cell of fore wing without a dark brown spot; ovipositor with two arch-like parts (Southern China) (Fig. 11) ....... Undabracon cariniventris sp. $\mathrm{n}$.

\subsubsection{Undabracon cariniventris sp.n.(Figs. 1a-l)}

Material examined. Holotype female, "[South China]: Province Guangxi, Baise, 2.vi.1982, He Jun-hua".

Holotype female. Length of body $7.1 \mathrm{~mm}$, fore wing $8.0 \mathrm{~mm}$, ovipositor (part exerted beyond apex of metasoma) $3.5 \mathrm{~mm}$.

Head. Antenna as long as fore wing, with 54 segments; scapus longer ventrally than dorsally, weakly emarginated apico-laterally, its length 1.9 times its depth apically (Fig.1h); length of first flagellomere 1.5 times its maximum width, and 0.4 times length of scapus; apical flagellomere acuminate, 2.2 times as long as its maximum width and 1.4 times length of penultimate flagellomere (Fig. 1i); length of penultimate flagellomere 1.5 times its 
width; third segment of maxillary palp of female 3.7 times as long as its maximum width; height of clypeus:inter-tentorial distance:tentorio-ocular distance $=5: 7: 4$ (Fig. 1a); central area of face longitudinally rugulose, with one distinct triangular carina extending to antennal sockets (Fig. 1a); height of face (distance between clypeus and antennal sockets): width of face: width of head $=6: 5: 14$ (Fig. 1a); frons distinctly impressed (Fig.1b); shortest distance between posterior ocelli:transverse diameter of posterior ocellus:shortest distance between posterior ocellus and eye $=3: 2: 3.5$ (Fig. 1b); vertex smooth and shiny.

Mesosoma. Mesosoma 1.70 times as long as high, smooth and shiny (Fig. 1c); notauli weakly impressed anteriorly, sparsely setose along the whole length; scutellar sulcus narrow and short, with distinct punctation and fine crenulation (Fig. 1c); metanotum with a wide carina medioposteriorly; propodeum smooth and shiny medially, with long setae laterally.

Wings. Fore wing (Fig. 1d): length of pterostigma 2.9 times its maximum width; vein cu-a of fore wing far antefurcal; vein $r$ arising half way of pterostigma; length of vein 1-SR 3.8 times vein $1-\mathrm{M}$; lengths of veins 2-SR+M:2-M:m-cu = 3.5:33:6; vein 1-SR+M distinctly curved basally; vein 2-CU1 distinctly thickened; lengths of veins 1-CU1:2-CU1:3-CU1 = 5:18:7; lengths of veins SR 1:3-SR:r = 7:5:1, lengths of veins 2-SR:3SR:r-m = 10:25:8. Hind wing (Fig. 1e): apex of vein $\mathrm{C}+\mathrm{SC}+\mathrm{R}$ with 3 bristles; vein $2-\mathrm{SC}+\mathrm{R}$ longitudinal and short, approximately 0.33 times vein 1r-m; vein SR curved; minimum width of marginal cell 0.5 times its apical width; basal cell usually with a distinct glabrous area distally; lengths of veins $\mathrm{SC}+\mathrm{R} 1: 1 \mathrm{r}-\mathrm{m}=19: 5$.

Legs. Lengths of femur:tibia:tarsus of fore leg $=25: 26: 29$; length of fore femur 6.1 times its maximum width; hind coxa smooth; hind tibia with a shallow lateral longitudinal depression; length of femur:tibia:basitarsus of hind leg $=30: 44: 15$ (Fig. 1j); lengths of hind femur and tibia 5.1 and 7.3 times their width, respectively; length of hind basitarsus 2.1 times length of hind inner tibia spur (Fig. 1j).

Metasoma. Tergites with dense and short setae, densely granulate and punctated (Figs. 1f, 1g); length of first tergite 0.9 times its apical width; medio-longitudinally raised area of first tergite smooth basally, rugulose and striate apically (Fig. 1f); second metasomal tergite with mid-basal raised triangle area surrounded by crenulate grooves; second metasomal suture deep and crenulate (Fig. 1f); third tergite with raised areas antero-laterally at either side, and weakly raised area medio-basally; fourth tergite with raised areas antero-laterally, but distinctly weak; fifth-seventh tergites rugulose and striate, without raised area antero-laterally; hypopygium pointed apically and not protruding behind the apex of metasoma; length of ovipositor as long as metasoma, and 0.5 times that of the body, with two distinctly arch-like areas apically (Fig. 11).

Colour. Body largely pale yellow, wing membrane yellow; middle part of vein 2-1A brown; 3rd to 5th metasomal tergites dark brown anterolaterally, and yellowish brown medially; hind coxa, femur and ovipositor sheath dark brown.

Diagnosis. This new species is similar to Undabracon sinuatus (Baltazar), their differences are listed in the above key.

\subsection{Genus Aphrastobracon Ashmead}

Aphrastobracon Ashmead, 1896: Proc. U.S. Nat. Mus. 18: 646; Watanabe (1950): J. Fac. Agric. Hokkaido (imp.) Univ. 48: 291-304; Baltazar (1963): Pacific. Ins. 5: 577-582; Tobias (1971): Trudý Vse. Ént. Obshchestva 54: 214; Papp (1972): Folia Ent. Hung., 25: 307; Shenefelt (1978): Hymen. Cat. (nov. editio) part 15: 1426-1430; Quicke (1987): J. Nat. Hist. 21: 100; Falco \& Quicke (1997): Eur. J. Ent. 94: 547; Quicke et al. (2000): African Ent. 8: 109-111; Papp (2001): Reichenbuchia Mus. Tierkunde Dresden 30: 167-168. Type species (monobasic): Aphrastobracon flavipennis Ashmead.

In Shenefelt's Hymenopterorum Catalogue, the genus Aphrastobracon Ashmead comprised a total of 34 species distributed throughout the Old World tropics (Shenefelt 1978), but fourteen species were transferred to either Curriea Ashmead or Iphiaulax Foerster by Falco and Quicke (1997) and Quicke et al. (2000). Therefore, there are ca. 20 valid species in this genus at present.

One species of this genus (from India) has been recorded as a larval ectoparasitoid of the entomophagous noctuid Eublemma Hübner, 1821 (Lepidoptera: Noctuidae: Eustrotinae) that attacks coccoids including the lac scale insect Kerria lacca (Kerr) (Hemiptera: Coccoidea: Kerridae) (Ramakrishna 1926, Quicke et al. 2000). 


\subsubsection{Aphrastobracon huanjiangensis sp.n. (Fig. $2 a-g$ )}

Material examined. Holotype female. "[South China]: Province Guangxi, Huanjiang, 1.v.1981, Zhou Zhihong”. Paratype: 1 female, "[South China]: Province Hunan, Nanmi, 8.vi.1980, Dong Xin-wang”.

Holotype female. Length of body $9.8 \mathrm{~mm}$, fore wing $10.5 \mathrm{~mm}$, ovipositor sheath $2.4 \mathrm{~mm}$.

Head. Antenna with 65 segments; scapus with dense long setae, its length 2.3 times its apical width; length of first flagellomere 1.4 times its maximum width; apical flagellomere pointed, 2.2 times as long as its maximum width and 1.3 times length of penultimate flagellomere; penultimate flagellomere 1.8 times as long as wide; third segment of maxillary palp 4.1 times as long as its maximum width; tentorio-ocular distance:intertentorial distance:height of clypeus $=7: 9: 11$ (Fig. 2a); face densely granulate and without carina or depression (Fig. 2a); height of face (distance between clypeus and antennal sockets): width of face: width of head $=14: 15: 40$ (Fig. 2a); frons distinctly impressed; shortest distance between posterior ocelli:transverse diameter of posterior ocellus:shortest distance between posterior ocellus and eye $=4: 2.5: 4$ (Fig. 2b); vertex largely smooth and shiny, and sparsely setose posterolaterally.

Mesosoma (Fig. 2c). Length of mesosoma 1.78 times its height, smooth, shiny and sparsely setose laterally; notauli weakly impressed and complete; scutellar sulcus narrow and distinctly crenulate; metanotum with a weak carina posteriorly; propodeum smooth and shiny, with long setae laterally and shallow depression medially.

Wings. Fore wing (Fig. 2d): vein 1-SR+M weakly curved distally; length of vein 1-SR 0.5 times vein 1-M; lengths of veins 2-SR+M:2-M:m$\mathrm{cu}=4: 36: 15$; lengths of veins 1 -CU1:2-CU1:3CU1 = 10:20:9; lengths of veins SR1:3-SR:r = 55:19:10; lengths of veins 2-SR:3-SR:r-m = 15:19:12; veins 1-CU1, CU1b and base of vein 1$M$ strongly expanded. Hind wing (Fig. 2e): vein $\mathrm{C}+\mathrm{SC}+\mathrm{R}$ with dense long thickened setae basally; vein $2-\mathrm{SC}+\mathrm{R}$ longitudinal; vein $1 \mathrm{r}-\mathrm{m}$ weakly curved basally; lengths of veins $\mathrm{SC}+\mathrm{R} 1: \mathrm{r}-\mathrm{m}=31: 9$.

Legs. Lengths of femur:tibia:basitarsus of fore leg $=31: 35: 18$; lengths of fore femur and tibia 5.1 times and 8.3 times their widths, respectively;

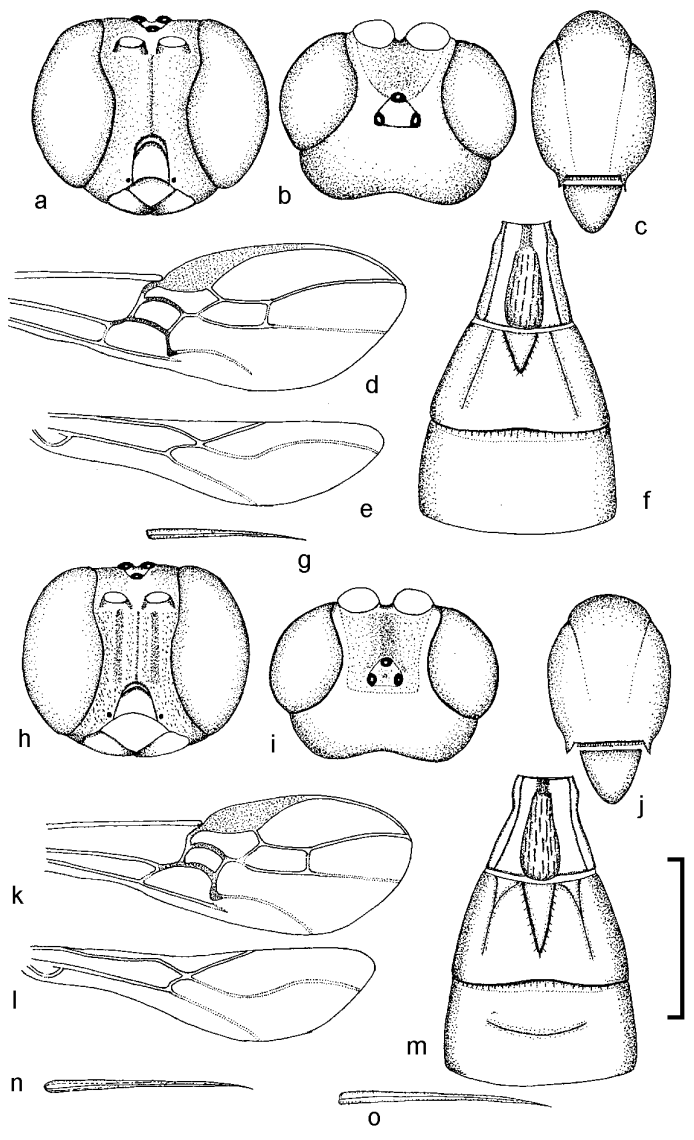

Fig. 2. - a-g. Aphrastobracon huanjiangensis sp. n., holotype female. - h-n. Aphrastobracon politus sp. n., holotype female. - o. Aphrastobracon philippinensis Baker. $\mathrm{a}, \mathrm{h}=$ head, frontal aspect; b, i = head, dorsal aspect; $\mathrm{c}, \mathrm{j}=$ mesothorax, dorsal aspect; $d, k=$ fore wing; $e, l=$ hind wing; $f, m=$ firstthird metasomal tergites, dorsal aspect; $\mathrm{g}, \mathrm{n}$, $0=$ ovipositor. Figure o redrawn after Baltazar (1963). Scale bar: $2 \times(a-f, h-m) ; 0.5 \times(g, n)$.

hind coxa shiny, with dense, long setae; lengths of femur:tibia:basitarsus of hind leg $=46: 63: 31$; lengths of hind femur and tibia 3.7 times and 8.9 times their maximum widths, respectively; hind femur sparsely setose, and tibia with dense short setae.

Metasoma (Fig. 2f). Metasoma densely setose; length of first tergite 1.2 times its apical width, apical raised area with shallow depression medially and short setae laterally; second tergite with basal-median triangular area surrounded by crenulate groove, which extends approximately 
to two-fifths of median length of second tergite; second metasomal suture deep medially and shallow laterally; third tergite without transverse groove sub-posteriorly; fourth-sixth tergites with moderately dense setae and without transverse grooves sub-posteriorly; length of ovipositor 0.25 times that of body.

Colour. Body yellow except antenna; venation, hind tibia and tarsus dark brown.

Diagnosis. This species is similar to A. flavipennis Ashmead, but differs from the latter by the characters as follows: body largely yellow; vein 1-SR of fore wing basally without dark brown spots (Figs. 2d, 2e); length of ovipositor 0.25 times that of body; apex of ovipositor relatively sharper and slender (Fig. 2g).

\subsubsection{Aphrastobracon politus sp. n. (Fig. $2 h-n)$}

Material examined. Holotype female, "[Central China]: Province Henan, Yichuan, 1112.vii.1996, Cai Ping". Paratype: 10", "[East China]: Hangzhou, 26.vi.1937, Chu Joo-Tso".

Holotype female. Length of body $6.7 \mathrm{~mm}$, fore wing $9.5 \mathrm{~mm}$, ovipositor (part exserted beyond apex of metasoma) $2.6 \mathrm{~mm}$.

Head. Antenna broken, with 50 segments remaining; length of scapus 2.0 times its apical width; length of first flagellomere 1.3 times its maximum width, and 0.5 times length of scapus; third segment of maxillary palp of female 3.8 times its maximum width; height of clypeus:inter-tentorial distance:tentorio-ocular distance $=6: 8: 4$ (Fig. 2h); face granulate, with longitudinal carina distinctly extending to between the antennal socket (Fig. 2h); height of face (distance between clypeus and antennal socket):width of face:width of head $=15: 12: 34$ (Fig. 2h); frons strongly impressed; shortest distance between posterior ocelli: transverse diameter of posterior ocellus:shortest distance between posterior ocellus and eye $=3: 2: 4$ (Fig. 2i); vertex smooth and shiny, without setae.

Mesosoma (Fig. 2j). Length of mesosoma 1.75 times its height, smooth and shiny; notauli weakly impressed on anterior half, and absent posteriorly; scutellar sulcus wide and deep, distinctly crenulate; metanotum with carina medio-posteriorly; propodeum smooth, shiny and with dense long setae laterally.
Wings. Fore wing (Fig. 2k): vein cu-a far antefurcal; vein 1-SR+M strongly curved distally; length of vein 1-SR 0.5 times vein 1-M; lengths of veins 2-SR+M:2-M:m-cu = 4:32:13; lengths of veins 1-CU1:2-CU1:3-CU1 = 10:17:8; lengths of veins SR1:3-SR:r = 53:25:8; lengths of veins 2SR:3-SR:r-m = 13:25:10; veins 1 -CU1 and $\mathrm{m}-\mathrm{cu}$ strongly expanded; vein CU1b expanded close to intersection of veins 3-CU1 and CU1a. Hind wing (Fig. 21): apex of the vein $\mathrm{C}+\mathrm{SC}+\mathrm{R}$ with one bristle; vein SR curved; vein 2-SC+R short and transverse; lengths of veins $1 \mathrm{r}-\mathrm{m}: \mathrm{SC}+\mathrm{R} 1=4: 15$.

Legs. Lengths of fore femur:tibia:basitarsus = 24:33:13; lengths of fore femur and tibia 4.8 and 8.2 times their widths, respectively; hind coxa smooth and shiny; lengths of hind femur: tibia:basitarsus $=4: 6: 2.3$; lengths of hind femur and tibia 3.9 times and 9.8 times their maximum widths, respectively; hind femur with long sparse setae, and tibia densely, shortly setose.

Metasoma (Fig. 2m). First tergite as long as wide apically; median raised area smooth and shiny; second tergite with triangular area mediobasally surrounded by crenulate grooves that extends approximately to four-fifths of median length of second tergite, and with sub-parallel longitudinal grooves laterally; second suture wide medially, and narrow laterally; third tergite with transverse weak groove medially; fourth-sixth tergites smooth and shiny, moderately densely and evenly setose laterally, without transverse or longitudinal grooves; length of ovipositor 0.4 times that of body.

Colour. Body yellow except antennae; venation, hind tibia, tarsus and ovipositor sheath dark brown.

Diagnosis. This species is similar to $A$. philippinensis Baker, but differs from it by the following characters: second tergite with triangular area medio-basally surrounded by crenulate grooves that extends approximately to four-fifths of media length of second metasomal tergite, and with sub-parallel longitudinal grooves laterally (Fig. $2 \mathrm{~m}$ ); length of ovipositor 0.4 times that of body.

\subsubsection{Aphrastobracon flavipennis Ashmead (Fig. 3a-c)}

Aphrastobracon flavipennis Ashmead, 1896: Proc. U.S. Nat. 
Mus. 18: 648; Watanabe (1950): J. Fac. Agric. Hokkaido (imp.) Univ. 48: 294; Tobias (1971): Trudý Vse. Ént. Obshchestva 54: 214; Papp (1972): Folia Ent. Hung. 25: 307; Shenefelt (1978): Hym. Cat. (nov. editio) part 15: 1427.

Material examined. 2 우, “[South China]: Province Guangdong, Xiu-wen, 19.ix.1980, Zou Xingen; Province Fujian, Kangshang, 9.ix.1983, Wang Jia-she".

Hosts. According to Shenefelt (1978), the actual hosts were Eublemma amabilis Moore, Eublemma coccidiphaga Hmps. and Eublemma scitula Ramb. (Lepidoptera: Noctuidae).

Distribution. China (Fujian, Guangdong), Ceylon, India.

\subsubsection{Aphrastobracon philippinensis Baker, 1917}

This species was previously reported from Formosa, Taiwan by Watanabe (1950), but no specimens were available for this study.

\subsection{Genus Curriea Ashmead, 1900}

Curriea Ashmead, 1900: Proc. U.S. Nat. Mus. 23: 137; Fahringer (1928): Opusc. Bracon. 2: 154; Watanabe (1937): J. Fac. Agric. Hokkaido (imp.) Univ. 42: 15; Papp (1972): Folia Ent. Hung., 25: 307; Shenefelt (1978): Hym. Cat. (nov. editio) part 15: 1426-1430; Quicke (1987): J. Nat. Hist. 21: 109; Falco \& Quicke (1997): Eur. J. Ent. 94: 547-552; Quicke et al. (2000): African Ent. 8: 109-139. Type species (monobasic and original designation): Curriea fasciatipennis Ashmead.

Endovipio Turner, 1922: Ann. Mag. Nat. 10: 270-271; Shenefelt (1978): Hym. Cat. (nov. editio) part 15: 1430; Quicke (1987): J. Nat. Hist. 21: 110; Falco \& Quicke (1997): Eur. J. Ent. 94: 549; Quicke et al. (2000): African Ent. 8: 138. Type species (monotype): Endovipio ceresensis Turner, syn. by Falco \& Quicke (1997).

Curriea Ashmead is a medium-sized genus with 34 species distributed in the Palaearctic, Afrotropical and Australian Regions, with the majority of the species confined to the tropics (Falco \& Quicke 1997, Quicke et al. 2000, Papp 2001). Of these, 14 species were recently transferred from Aphrastobracon (Quicke 2000). The genus Curriea is closely related to Aphrastobracon. Nothing is known about the biology of this genus at present.

The species Curriea tibialis (Ashmead) is reported from China for the first time in this paper.

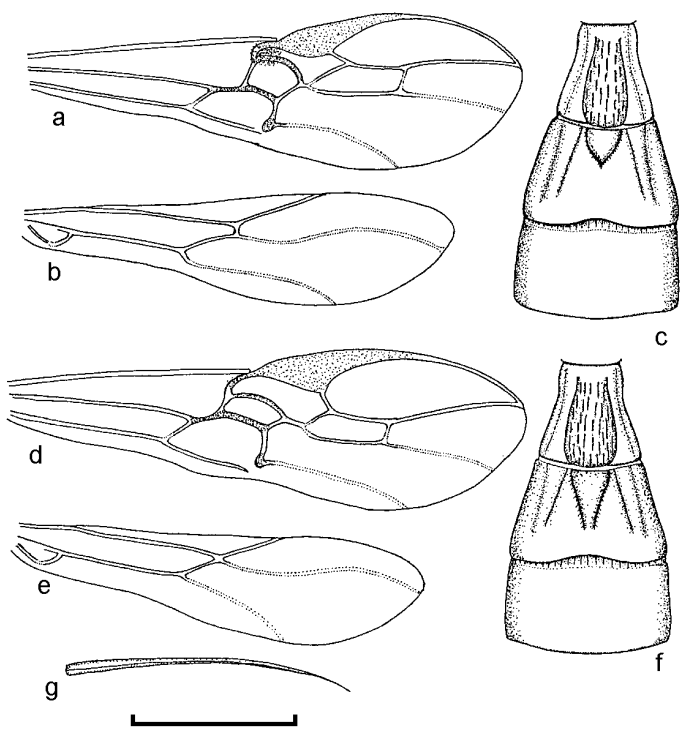

Fig. 3. - a-c. Aphrastobracon flavipennis Ashmead. d-g. Curriea tibialis (Ashmead). $a, d=$ fore wing; $b, e=$ hind wing; $c, f=$ first-third metasomal tergites, dorsal aspect; $\mathrm{g}=$ ovipositor. Scale bar: $2 \times(\mathrm{a}-\mathrm{f}) ; 0.5 \times(\mathrm{g})$.

\subsubsection{Curriea tibialis (Ashmead) (Fig. 3d-g)}

Melanobracon tibialis Ashmead, 1906: Proc. U.S. Nat. Mus. 30: 159.

Atanycolus tibialis Fahringer, 1928: Opusc. Bracon. 1: 519. Curriea tibialis Watanabe, 1937: J. Fac. Agric. Hokkaido (imp.) Univ. 42: 15; Quicke (1997): Eur. J. Ent. 94: 548.

Aphrastobracon tibialis Watanabe, 1950: J. Fac. Agric. Hokkaido (imp.) Univ. 48: 294; Shenefelt (1978): Hym. Cat. (nov. editio) part 15: 1430.

Material examined. 5 females, "[South China]: Province Guangxi, Jinxiu, 19.ix.1980, Huang Chong-rong"; "Province Zhejiang, W. Mt. Tianmu, 3.vi.1999, 22.vi.1999, 21.vii.1998, 28.vii.1998, Zhao Ming-shui, light trapping".

Distribution. China (Zhejiang, Guangxi), Japan.

Acknowledgements. We wish to thank Dr Donald L. J. Quicke (London, U.K.), C. van Achterberg (Leiden, The Netherlands) and Jenö Papp (Budapest, Hungary) for providing their literature. This study was funded by the National Natural Science Foundation of China (No. 30170120).

\section{References}

Achterberg, C. van 1979: A revision of the subfamily Zelinae auct. (Hymenoptera: Braconidae). - Tijdschr. Ent. 122: 241-479. 
Ashmead, W. H. 1896: On some reared Parasitic Hymenopterous Insects from Ceylon. — Proc. U.S. Nat. Mus. 18: 644-648.

Ashmead, W. H. 1900: Classification of the ichneumon flies, or the superfamily Ichneumonoidea. — Proc. U.S. Nat. Mus. 23: 1-120.

Ashmead, W. H. 1906: Description of new Hymenoptera from Japan. — Proc. U.S. Nat. Mus. 30: 169-201.

Baltazar, C. R. 1963: A new genus and nine new species of Philippines Braconidae (Hymenoptera). - Pacific. Inst. 5: 577-589.

Fahringer, J. 1928: Opuscula Braconologica. Palaearktische Region. Lief. 1. F. Wagner, Wien.

Falco, J. V. \& Quicke, D. L. J. 1997: The genus Curriea in Europe and the Canary Islands (Hymenoptera: Braconidae: Braconinae). — Eur. J. Ent. 94: 547-552.

Papp, J. 1972: Aphrastobracon antefurcalis (Szépl), an Ethiopian braconid species caught near Rijeka, Yugoslavia (Hym., Braconidae ). — Folia Ent. Hung. 25: 307-311.

Papp, J. 2001: Taxonomic studies on six genera of Braconini (Insecta: Hymenoptera: Braconidae). — Reichenbachia Mus. Tierkunde Dresden 30: 167-169.

Quicke, D. L. J. 1986: Seven new genera and species of Braconinae (Hymenoptera, Braconidae) from Australia and Indonesia. - Ent. Mon. Mag. 122: 9-29.

Quicke, D. L. J. 1987: The old world genera of braconine wasps (Hymenoptera: Braconidae). — J. Nat. Hist. 21: 43-157.

Quicke, D. L. J. 1988: Higher classification, biogeography and biology of the Braconinae (Hymenoptera: Braconinae). - In: Gupta, V. K. (ed.), Advances in Parasitic Hymenoptera research: 117-138. E. J. Brill, Leiden.

Quicke, D. L. J. \& Ingram, S. N. 1993: Braconine wasps of Australia. - Mem. Queensland Mus. 33: 299-336.

Quicke, D. L. J., Brandt, A. P. \& Falco, J. V. 2000: Revision of Afrotropical species of Curriea Ashmead (Hymenoptera: Braconidae: Braconinae), a genus with diverse ovipositor morphology. — African Ent. 8: 109139.

Ramakrishna Ayyar, T. V. 1926. The braconid genus Aphrastobracon Ashmead. — Bull. Ent. Res. 17: 9198.

Shenefelt, R. D. 1978: Braconidae 10. - Hymenopterorum Catalogus (nov. editio), part 15, W. Junk, Hague. pp. 1425-1872.

Tobias, V. I. 1971: Review of the Braconidae (Hymenoptera) of the USSR. - Trudý Vse. Ént. Obshchestva. Akademiya Nauk SSSR 54: 156-269.

Turner, R. E. 1922: New Evaniidae and Braconidae in the British Museum. - Ann. Mag. Nat. Hist. 10: 270-281.

Watanabe, C. 1937: A contribution to the knowledge of the Braconidae Fauna of the Empire of Japan (Hymenoptera). — J. Fac. Agric. Hokkaido (imp.) Univ. Sapporo 42: $1-187$.

Watanabe, C. 1950: A preliminary revision of the genus Aphrastobracon Ashmead (Hymenoptera, Braconidae). — J. Fac. Agric. Hokkaido (imp.) Univ. Sapporo 48: 291-304. 